\title{
EFFICACY OF DIFFERENT IRRIGATING SYSTEMS WITH A NEW IRRIGATING SOLUTION IN REDUCING INTRACANAL ENTEROCOCCUS FAECALIS
}

\author{
Ahmed A .M. Abdel Latif*; Medhat A. Katiaa**; Hayam Y.M. Hassan ${ }^{* * *}$ and Marwa M. Azab ${ }^{* * * *}$
}

\begin{abstract}
Aim: The aim of the present study was to evaluate the effect of $\mathrm{QMix}^{\mathrm{TM}} 2 \mathrm{in} 1$ in comparison with sodium hypochlorite irrigating solution on Enterococcus faecalis using different irrigation systems namely: Passive irrigation, ultrasonic activation, sonic activation.

Materials and methods: 70 freshly extracted human single rooted teeth were collected. Root canals were prepared using Protaper Universal NiTi rotary file system in a crown down technique. Enterococcus Faecalis bacterial suspension in Trypticase soy broth was applied into the canal of each root. 65 Teeth were randomly divided into 3 experimental groups of 20 teeth each according to the technique used during irrigation protocol and a control group of 5 teeth without irrigation. Each group was subdivided into two sub-groups according to the type of irrigant. Samples were divided into four time intervals; S1 sample was taken immediately after infection of the teeth, S2 sample was taken immediately after irrigation, S3 sample was taken after 3 days incubation period after irrigation of the teeth, S4 sample was taken after 10 days from the infection. The method of evaluation of antimicrobial activity used was direct counting of colony forming units (CFUs) after irrigation.
\end{abstract}

Results: there was increase in the bacterial count reduction with no statistical difference between QMixTM2in1 and 2.5\% $\mathrm{NaOCl}$ after 3 days period from the irrigation procedures, while there was increase in the effect of QMixTM2in1 over $2.5 \% \mathrm{NaOCl}$ after 10 days from irrigation procedures. While there wasn't any difference found between the three agitation techniques on the antibacterial activity of both irrigants used.

Conclusions: QMixTM2in1 irrigating solution proved antimicrobial efficacy in short and prolonged duration against Enterococcus faecalis. The antimicrobial efficiency of sodium hypochlorite can be improved using full concentration. It was also concluded that different agitation techniques have no effect on the antimicrobial efficacy.

KEYWORDS: Irrigation, Enterococcus faecalis, QMixTM2in1, Max-I-probe, Endoactivator, ultrasonic activation.

\footnotetext{
* Candidate, Master's Degree Program, Endodontic Dept., Faculty of Dentistry, Suez Canal University.

** Professor of Endodontics, Faculty of Oral and Dental Medicine, Cairo University.

*** Lecturer in Endodontics, Faculty of Dentistry, Suez Canal University.

**** Lecturer in Microbiology and Immunology, Faculty of Pharmacy, Suez Canal University.
} 


\section{INTRODUCTION}

Many microorganisms are able to form surfaceattached microbial communities, known as biofilms. Biofilms can be defined as communities of microorganisms attached to a surface and embedded in a matrix of polysaccharides and proteins forming a slimy layer. The matrix takes $85 \%$ of the volume of biofilm ${ }^{(1,2)}$. Enterococcus faecalis regarding its role in root canal treatment failure where it is a microorganism commonly detected in asymptomatic, persistent endodontic infections (3) Irrigants are essential for successful debridement of the root canals ${ }^{(4)}$.Sodium hypochlorite $(\mathrm{NaOCl})$ has been widely used as an irrigant since its introduction in endodontics. The antimicrobial activity of $\mathrm{NaOCl}$ has been shown by several studies ${ }^{(5-7)}$. Another new antimicrobial root canal irrigant QMixTM2in1 containing a mixture of a bisbiguanide antimicrobial agent, a polyamino-carboxylic acid, calciumchelating agent, and a surfactant have been found to be effective against bacterial biofilms have been found to be effective against bacterial biofilms ${ }^{(8)}$. All irrigants must be brought into direct contact with the entire canal wall for effective action ${ }^{(9)}$. Tronstad et al ${ }^{(10)}$ were the first to report the use of a sonic instrument for endodontics in 1985. One of the recent sonic driven canal irrigation devices is the endoactivator system that uses sonic energy to irrigate root canal systems ${ }^{(11)}$. Richman (12) was the first to describe the use of ultrasonics for cleaning the root canal. Ultrasonic devices operate between $25-40 \mathrm{kHz}$ transforming electrical and electromagnetic energy into mechanical energy. The term Passive ultrasonic irrigation (PUI) was first used by Weller ${ }^{(13)}$. Accordingly, a study comparing the antimicrobial effect of the previously mentioned irrigants using different activation protocols may enlighten our knowledge.

\section{MATERIALS AND METHODS}

70 freshly extracted human single rooted teeth were collected. Root canals were prepared using Protaper Universal NiTi rotary file system (Dentsply
Maillefer, Ballaigues, Switzerland) in a crown down technique. A strain of Enterococcus faecalis (ATCC 29212) (Central Health Laboratories, Cairo) was used as a tested organism. Morphological figures on M-Enterococcus agar plates were formed. They appeared as pink rounded colony growth, and microscopically using gram staining technique. The Isolated 24-hours colonies of pure culture of Enterococcus faecalis were suspended in $20 \mathrm{ml}$ of trypticase soy broth TSB (Oxoid Ltd, Basingstoke, United Kingdom.) and incubated for 24 hours at $37 \mathrm{OC}$ until the optical density of the bacterial suspension was adjusted to approximately $3 \times 108$ $\mathrm{CFU} / \mathrm{ml}$, by comparing its turbidity to $1 \mathrm{McFarland}$ standard.

Under aseptic conditions, $10 \mu \mathrm{l}$ of the previously prepared bacterial suspension was applied into the canal of each root using an automatic Eppendorf micropipette (Kopenicker, Bad Durkheim, Germany). The coronal access of all samples were sealed with pink wax and enclosed individually within sterile Eppendorf tubes (Elkay, Shrewbury, MA, USA) held vertically in a perforated tray. They were incubated at $37^{\circ} \mathrm{C}$ for seven days to give time for bacteria to infiltrate deeply within the dentinal tubules. $10 \mu \mathrm{l}$ of sterile TSB was added on the third day during the incubation period, to maintain bacterial survival, overcome dehydration and to maintain a constant source of nutrition for the bacteria.

\section{The first sample for bacterial count (S1):}

After seven days of incubation period the wax of the coronal access was removed and the first sample (S1) was taken as follows: Sterile $1.5 \mathrm{ml}$ Eppendorf tubes containing $1 \mathrm{ml}$ saline were previously prepared and labelled corresponding to the sample number. $20 \mu \mathrm{l}$ of sterile saline was taken by sterile filter tips* mounted using an automatic micropipette from each labelled Eppendorf. Tips are applied and the saline is washed several times inside the root canal of the suggested sample. Dispersion of saline solution back in the previously labelled Eppendorf 
is done. This procedure is done several times for all S1 samples. For each sample $100 \mu 1$ was streaked on agar plates. For uncounted sample one excess step was performed as $10 \mu \mathrm{l}$ taken from the previous sample is diluted on $1 \mu 1$ sterile saline then $100 \mu 1$ is streaked on the agar plates.

Colony forming units (CFU) was used to determine the number of viable bacterial cells in a sample per $\mathrm{ml}$. This was done by using a small amount of a liquid culture and plating out several serial dilutions onto culture plates Petri dishes containing M- Enterococcus agar medium). After 3 days incubation period in appropriate conditions for Enterococcus faecalis, the colonies grown were counted.

\section{A. Grouping of teeth according to the mode of irrigation:}

Sixty five samples were randomly divided into 4 groups $(n=20)$ each according to the irrigation technique used:

- Group A: were irrigated using Max-I-Probe (Dentsply-Rinn, Elgin, IL), (n=20).

- Group B: were irrigated using Endoactivator (Dentsply Tulsa Dental Specialities, Tulsa, Ok), $(n=20)$.

- Group C: were irrigated using Ultrasonic device (Acetone Group, Merigance Codex, France), $(n=20)$.

- Group D: control group didn’t receive any type of irrigation $(n=5)$.

Each group is equally subdivided into two subgroups (each $n=10$ ) according to the irrigant used as follows:

- Subgroup $\left(\mathrm{A}_{1}, \mathrm{~B}_{1}\right.$, and $\left.\mathrm{C}_{1}\right)$ : irrigation was done with $2.5 \% \mathrm{NaOCl}$ (Oxford Laboratory, Mumbai, Maharashtra, India).

- Subgroup $\left(\mathrm{A}_{2}, \mathrm{~B}_{2}\right.$, and $\left.\mathrm{C}_{2}\right)$ : irrigation was done with QMix ${ }^{\mathrm{TM}} 2$ in1 (DentsplyTusla Dental Specialities, Oklahoma,USA) full concentration.

\section{Irrigation Protocol of group A (Max-I-Probe) $(n=20)$}

Specimens in subgroup (A1) $(2.5 \% \mathrm{NaOCL})$ were subjected to, a three cycles 20 seconds each as follows:

First- 20 seconds cycle: teeth were irrigated using 30-gauge side vented needle mounted on a syringe. The syringe was filled with the irrigating solution and the needle was introduced in the canal without wedging and evacuated with light hand pressure. The other two cycles was performed as the first cycle with a total volume of $3 \mathrm{ml}$ for 1 min. Specimens in subgroup (A2) (QMixTM2in1) were subjected to three cycles 20 seconds each as previously mentioned.

\section{Irrigation protocol of group B (Endoactivator) $(n=20)$}

Specimens in subgroup (B1) $(2.5 \% \mathrm{NaOCl})$ were subjected to three activation cycles 20 seconds each as follows:

First 20 seconds cycle: teeth were irrigated with $1 \mathrm{ml}(2.5 \% \mathrm{NaOCl})$ followed by activation with the Endoactivator at 10,000 cycles per minute with a \#25/04 polymer tip(Dentsply Tulsa Dental Specialities, Tulsa, Ok ) placed $1 \mathrm{~mm}$ shorter than the working length. A new sterile tip was used for each sample. The other two cycles was performed as the first cycle with a total volume of $3 \mathrm{ml}$ for 1 min. Specimens in subgroup (B2) (QMixTM2in1) were subjected to three activation cycles 20 seconds each as previously mentioned.

\section{Irrigation protocol of group $C$ (ultrasonic) $(n=20)$}

Specimens in subgroup (C1) $(2.5 \% \mathrm{NaOCl})$ were subjected to three activation cycles 20 seconds each as follows:

First 20 seconds: teeth were irrigated with $1 \mathrm{ml}$ $(2.5 \% \mathrm{NaOCl})$ then activated by Irrisafe ultrasonic tip (Acetone Group, Merigance Cedex, France) 
mounted on Satelec ultrasonic device at power setting of 5 placed $1 \mathrm{~mm}$ shorter than the working length. A new sterile tip was used for each sample. The other two cycles was performed as the first cycle with a total volume of $3 \mathrm{ml}$ for $1 \mathrm{~min}$. Specimens in subgroup (C2) (QMixTM2in1) were subjected to three activation cycles 20 seconds each as previously mentioned.

\section{The second sample for bacterial count (S2):}

Immediately after irrigation procedures the second sample for bacterial count (S2) was taken from each root canal by the same way as in S1 then aliquots (drops) of $0.1 \mathrm{ml}$ were plated onto M-Enterococcus agar plates and incubated at $37^{\circ} \mathrm{C}$ for $48 \mathrm{~h}$. The appearance of red colonies represented the colonies of viable Enterococcus faecalis which were counted and recorded.

\section{The second incubation period:}

After the second sample for bacterial count was taken each root canal was filled with $20 \mu 1$ sterile TSB and the coronal access was sealed with melted pink wax and all the samples were enclosed individually within sterile Eppendorf tubes and held vertically in a perforated rack. They were incubated at $37^{\circ} \mathrm{C}$ for three days.

\section{The third sample for bacterial count (S3):}

After three days incubation period the third sample for bacterial count (S3) of each root canal was taken by the same way as in S1 and S2 and data obtained from S3 were also counted and recorded.

\section{The third incubation period:}

After the third sample for bacterial count was taken each root canal was filled with $20 \mu 1$ sterile TSB and the coronal access was sealed with melted pink wax and all the samples were enclosed individually within sterile Eppendorf tubes and held vertically in a perforated rack. They were incubated at $37^{\circ} \mathrm{C}$ for another seven days to check the prolonged action of the irrigating solutions after 10 days from the irrigation procedures.

\section{The fourth sample for bacterial count (S4):}

After seven days incubation period the fourth sample for bacterial count (S4) of each root canal was taken by the same way as in S1, S2 and S3 data obtained from $\mathrm{S} 4$ were also counted and recorded.

Colony forming units (CFU) were calculated based on surface streaking inoculation using sterile cotton swab.

\section{Counting the resulting bacterial colonies.}

After appropriate incubation, plates were inspected and growth on the plates was reflected to the dilution. There were heavy plates and countable plates.

Each petri dish was divided into 4 equal squares and the number of bacteria was counted for one square and then multiplied $\mathrm{x} 4$ to estimate whole plate colony forming unit count. Countable limit of this procedure was 30 to 300 colonies per plate.

Counting was performed in the presence of magnifying light using a colony counter that counts by touching the agar directly and gives two signals an audible and a black dot on the plate and appearance of the colony numbers that was counted on the display.

The number and percentage of the positive cultures (turbid) and whole plate CFU count for each sample at each determined period were collected, recorded, tabulated and subjected to statistical analysis using Kruskal-Wallis, Mann-Whitney U, Friedman's and Wilcoxon signed-rank tests.

\section{RESULTS}

The following results represented the efficacy of three irrigation devices Max-I-Probe, Endoactivator and ultrasonic using 2.5\% $\mathrm{NaOCl}$ and $\mathrm{QMix}^{\mathrm{TM}}$ 2in1 in reducing intracanal Enterococcus faecalis at 
different time intervals. The time intervals were immediately after irrigation of the samples, three days after irrigation and ten days after irrigation.

Comparison between changes in bacterial counts by time within Max-I-Probe group using two irrigating solutions $(2.5 \% \mathrm{NaOCl}$ and QMix $^{\mathrm{TM}}$ 2in1).

Friedman's and Wilcoxon signed-rank statistical analysis compared changes in the mean bacterial count by time from (S1) to (S2) as well as from (S3) to (S4) within Max-I-Probe group using two irrigants $\left(2.5 \% \mathrm{NaOCl}\right.$ and $\left.\mathrm{QMix}^{\mathrm{TM}} 2 \mathrm{in} 1\right)$.

When using $2.5 \% \mathrm{NaOCl}$ irrigating solution (S4) recorded mean bacterial count $(9.05 \pm 0.08)$ followed by $(\mathrm{S} 1)(8.98 \pm 0.11),(\mathrm{S} 3)(3.88 \pm 2.68)$ then $(\mathrm{S} 2)(0.00 \pm 0.00)$ that showed no mean bacterial count. There was a statistically significant decrease in mean bacterial counts when using $2.5 \%$ $\mathrm{NaOCl}$ from (S1) to (S2). From (S2) to $(\mathrm{S} 3)$ as well as from (S3) to (S4) there was a statistically significant increase in mean bacterial counts as shown in table (1).

When using $\mathrm{QMix}^{\mathrm{TM}}$ 2in1 irrigating solution (S1) showed the highest mean bacterial count $(8.99 \pm$ $0.10)$ followed by (S4) (4.38 \pm 3.07$)$, (S3) (1.17 \pm $2.47)$ then $(\mathrm{S} 2)(0.00 \pm 0.00)$ that showed no bacterial count. There was a statistically significant decrease in mean bacterial counts when using $\mathrm{QMix}^{\mathrm{TM}} 2 \mathrm{in} 1$ irrigating solution from (S1) to (S2). From (S2) to (S3), there was no statistically significant change in mean bacterial counts. From (S3) to (S4) there was a statistically significant increase in mean bacterial counts as shown in table (1) and Fig. (1).

TABLE (1) Comparison between changes in mean bacterial counts by time within Max-I-Probe group using two irrigating solutions $\left(2.5 \% \mathrm{NaOCl}\right.$ and $\left.\mathrm{QMix}^{\mathrm{TM}} 2 \mathrm{in} 1\right)$.

\begin{tabular}{|c|c|c|c|c|}
\hline Irrigant & $\boldsymbol{S 1}$ & $\boldsymbol{S 2}$ & $\boldsymbol{S 3}$ & $\boldsymbol{S 4}$ \\
\hline $\mathbf{2 . 5 \%} \mathbf{~ N a O C l}$ & $8.98 \pm 0.11^{\mathrm{a}}$ & $0.00 \pm 0.00^{\mathrm{c}}$ & $3.88 \pm 2.68^{\mathrm{b}}$ & $9.05 \pm 0.08^{\mathrm{a}}$ \\
\hline $\mathbf{Q M i x}^{\mathrm{TM}} \mathbf{2 i n} \mathbf{1}$ & $8.99 \pm 0.10^{\mathrm{a}}$ & $0.00 \pm 0.00^{\mathrm{c}}$ & $1.17 \pm 2.47^{\mathrm{c}}$ & $4.38 \pm 3.07^{\mathrm{b}}$ \\
\hline
\end{tabular}

Significant at $P \leq 0.05$.

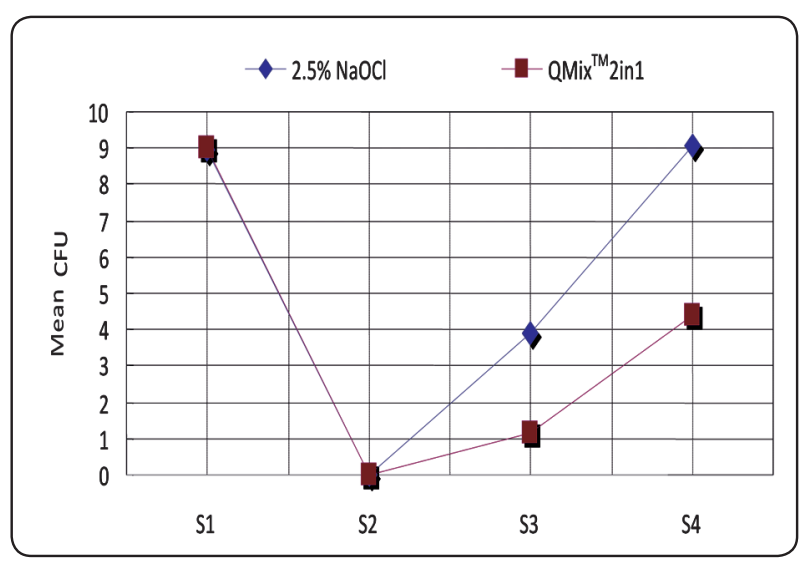

Fig. (1) Comparison between changes in mean bacterial counts by time within Max-I-Probe group using two irrigation solutions $\left(2.5 \% \mathrm{NaOCl}\right.$ and $\left.\mathrm{QMix}^{\mathrm{TM}} 2 \mathrm{in} 1\right)$.
Comparison between changes in bacterial counts by time within ultrasonic group using two irrigation solutions $\left(2.5 \% \mathrm{NaOCl}\right.$ and $\left.\mathrm{QMix}^{\mathrm{TM}} 2 \mathrm{in} 1\right)$.

Friedman's and Wilcoxon signed-rank statistical analysis compared changes in the mean bacterial count by time from (S1) to (S2) as well as from (S3) to (S4) within Ultrasonic group using two irrigants $\left(2.5 \% \mathrm{NaOCl}\right.$ and $\left.\mathrm{QMix}^{\mathrm{TM}} 2 \mathrm{in} 1\right)$.

When using 2.5\% $\mathrm{NaOCl}$ (S1) showed the highest mean bacterial count $(9.01 \pm 0.10)$ followed by (S4) $(9.00 \pm 0.09),(\mathrm{S} 3)(2.53 \pm 3.27)$ then $(\mathrm{S} 2)$ $(0.00 \pm 0.00)$ that showed no mean bacterial count. There was a statistically significant decrease in 
mean bacterial counts when using 2.5\% NaOCl irrigating solution from (S1) to (S2). From (S2) to $(\mathrm{S} 3)$ as well as from (S3) to (S4) there was a statistically significant increase in mean bacterial counts as shown in table (2).

When using $\mathrm{QMix}^{\mathrm{TM}}$ 2in1 irrigating solution (S1) showed the highest mean bacterial count $(9.01 \pm 0.10)$ followed by (S4) $(4.10 \pm 2.84)$, (S3) $(1.10 \pm 2.32)$ then $(\mathrm{S} 2)(0.00 \pm 0.00)$ that showed no mean bacterial count. There was a statistically significant decrease in mean bacterial counts when using $\mathrm{QMix}^{\mathrm{TM}} 2 \mathrm{in} 1$ irrigating solution from (S1) to (S2). From (S2) to (S3), there was no statistically significant change in mean bacterial counts. From (S3) to (S4) there was a statistically significant increase in mean bacterial counts as shown in table (2) and Fig. (2).
Comparison between changes in bacterial counts by time within Endoactivator group using two irrigating solutions $(2.5 \% \mathrm{NaOCl}$ and QMix $^{\mathrm{TM}}$ 2in1).

Friedman's and Wilcoxon signed-rank statistical analysis compared changes in the mean bacterial count by time from (S1) to (S2) as well as from (S3) to (S4) within Endoactivator group using two irrigating solutions $\left(2.5 \% \mathrm{NaOCl}\right.$ and $\left.\mathrm{QMix}^{\mathrm{TM}} 2 \mathrm{in} 1\right)$.

When using $2.5 \% \mathrm{NaOCl}$ (S4) recorded the highest mean bacterial count $(9.01 \pm 0.09)$ followed by (S1) $(8.98 \pm 0.09),(\mathrm{S} 3)(2.22 \pm 2.88)$ then $(\mathrm{S} 2)$ $(0.00 \pm 0.00)$ that showed no mean bacterial count There was a statistically significant decrease in mean bacterial counts when using $2.5 \% \mathrm{NaOCl}$ irrigating solution from (S1) to (S2). From (S2) to (S3) as

TABLE (2) Comparison between changes in mean bacterial counts by time within ultrasonic group using two irrigating solutions $\left(2.5 \% \mathrm{NaOCl}\right.$ and $\left.\mathrm{QMix}^{\mathrm{TM}} 2 \mathrm{in} 1\right)$.

\begin{tabular}{|c|c|c|c|c|}
\hline Irrigant & $\boldsymbol{S 1}$ & $\boldsymbol{S 2}$ & $\boldsymbol{S 3}$ & $\boldsymbol{S 4}$ \\
\hline $\mathbf{2 . 5 \%} \mathbf{N a O C l}$ & $9.01 \pm 0.10^{\mathrm{a}}$ & $0.00 \pm 0.00^{\mathrm{b}}$ & $2.53 \pm 3.27^{\mathrm{b}}$ & $9.00 \pm 0.09^{\mathrm{a}}$ \\
\hline $\mathbf{Q M i x}^{\mathrm{TM}} \mathbf{2 i n} \mathbf{1}$ & $9.01 \pm 0.10^{\mathrm{a}}$ & $0.00 \pm 0.00^{\mathrm{c}}$ & $1.10 \pm 2.32^{\mathrm{c}}$ & $4.10 \pm 2.84^{\mathrm{b}}$ \\
\hline
\end{tabular}

Significant at $P \leq 0.05$.

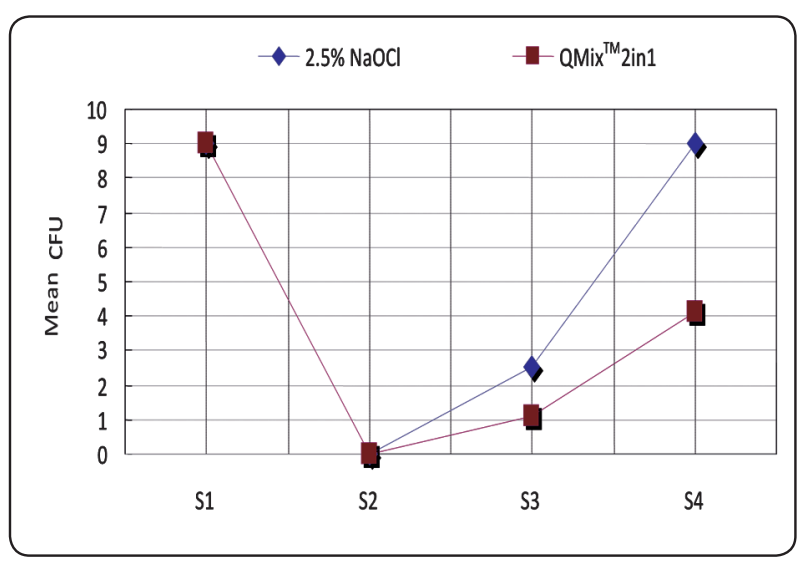

Fig. (2) Comparison between changes in mean bacterial counts by time within ultrasonic group using two irrigating solutions $(2.5 \% \mathrm{NaOCl}$ and QMixTM2in1). well as from (S3) to (S4) there was a statistically significant increase in mean of bacterial counts as shown in table (3).

When using $\mathrm{QMix}^{\mathrm{TM}} 2$ in1 irrigating solution (S1) recorded the highest mean bacterial count $(8.98 \pm 0.09)$ followed by (S4) $(4.27 \pm 2.99),(\mathrm{S} 3)$ $(1.14 \pm 2.40)$ then $(\mathrm{S} 2)(0.00 \pm 0.00)$ that showed no mean bacterial count. There was a statistically significant decrease in mean bacterial counts when using $\mathrm{QMix}^{\mathrm{TM}}$ 2in1 irrigating solution from (S1) to (S2). From (S2) to (S3), there was no statistically significant change in mean bacterial counts. From (S3) to (S4) there was a statistically significant increase in mean bacterial counts as shown in table (3) and Fig. (3). 
TABLE (3) Comparison between changes in mean bacterial counts by time within Endoactivator group using two irrigating solutions $\left(2.5 \% \mathrm{NaOCl}\right.$ and $\left.\mathrm{QMix}^{\mathrm{TM}} 2 \mathrm{in} 1\right)$.

\begin{tabular}{|c|c|c|c|c|}
\hline Irrigant & $\boldsymbol{S 1}$ & $\boldsymbol{S 2}$ & $\boldsymbol{S 3}$ & $\boldsymbol{S 4}$ \\
\hline $\mathbf{2 . 5 \%} \mathbf{N a O C l}$ & $8.98 \pm 0.09^{\mathrm{a}}$ & $0.00 \pm 0.00^{\mathrm{b}}$ & $2.22 \pm 2.88^{\mathrm{b}}$ & $9.01 \pm 0.09^{\mathrm{a}}$ \\
\hline $\mathbf{Q M i x}^{\mathrm{TM}} \mathbf{2 i n} 1$ & $8.98 \pm 0.09^{\mathrm{a}}$ & $0.00 \pm 0.00^{\mathrm{c}}$ & $1.14 \pm 2.40^{\mathrm{c}}$ & $4.27 \pm 2.99^{\mathrm{b}}$ \\
\hline
\end{tabular}

Significant at $P \leq 0.05$.

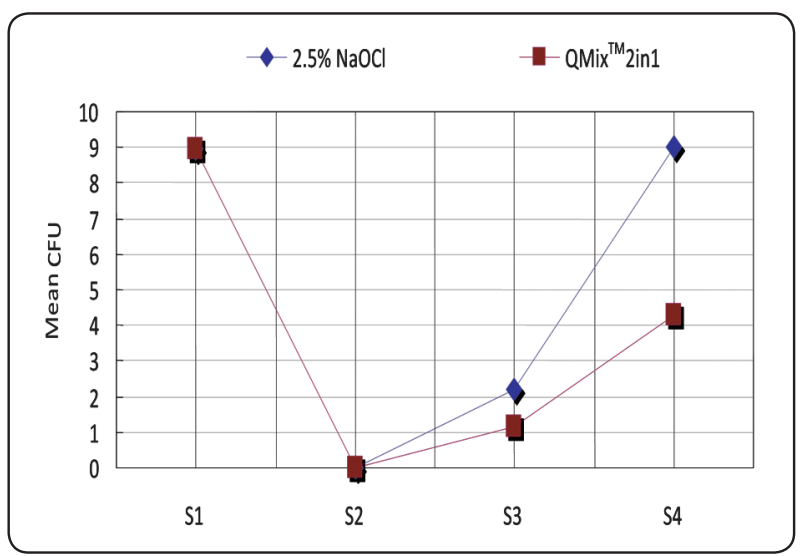

Fig. (3) Comparison between changes in mean bacterial counts by time within Endoactivator group using two irrigating solutions $\left(2.5 \% \mathrm{NaOCl}\right.$ and $\left.\mathrm{QMix}^{\mathrm{TM}} 2 \mathrm{in} 1\right)$.

\section{DISCUSSION}

Successful endodontic treatment depends mainly on proper cleaning, shaping and obturation of the root canal system. Earlier researches ${ }^{(1)}$ placed great emphasis on the bacterial contamination of the root canal as it is a major concern in endodontics. Elimination of microorganisms and necrotic tissues from the root canal system is essential for successful treatment outcome. The complexity of the root canal system as well as limitations of the used root canal irrigants makes this job difficult if not impossible. Some bacteria may remain in the far reached irregular areas of the root canal system as well as within the dentinal tubules, where they grow in the form of aggregates embedded in extracellular matrix material known as biofilm ${ }^{(2)}$.

Wang et $\boldsymbol{a l}^{(14)}$ concluded that within root canals, bacteria in established biofilm are less likely killed by endodontic irrigation and medication than bacteria in young biofilm.

In our present study Enterococcus faecalis microorganism was selected as it exhibits different characteristics as being gram-positive, nonsporeforming cocci that occur singly, in pairs, and in short chains. It is a facultative anaerobe and is found adapted to the complex environments of the oral cavity. Enterococcus faecalis has been occasionally detected in primary root canal infections (15). Researchers reported that Enterococcus faecalis can be found in several cases of persistent infections, including failed cases. It is apparent from the dental literature that Enterococcus faecalis often is difficult to eradicate with current intracanal medications ${ }^{(16,17)}$.

Historically, countless compounds in aqueous solution have been suggested as root canal irrigants. Thus, the purpose of this study was to evaluate the effect of $2.5 \%$ sodium hypochlorite in comparison with $\mathrm{QMix}^{\mathrm{TM}} 2$ in1 irrigating solution on Enterococcus faecalis using different irrigation systems namely: Passive irrigation, ultrasonic activation and sonic activation.

Sodium hypochlorite was chosen as an irrigant in the present study because it is the most widely accepted irrigant due to its effective antibacterial action, dissolution of organic materials and ease of removal from the canal. However, at high concentrations it is toxic and irritates the periapical tissues ${ }^{(18)}$.

The second selected irrigant is a new antimicrobial root canal irrigant $\mathrm{QMix}^{\mathrm{TM}} 2 \mathrm{in} 1$ that 
have been found to be effective against bacterial biofilms ${ }^{(8)}$. Multiple studies have shown superior antimicrobial effect of $\mathrm{QMix}^{\mathrm{TM}} 2 \mathrm{in} 1$ together with its ability in smear layer removal ${ }^{(19-22)}$.

Currently several techniques and systems are available and reported to improve final irrigation before obturation. Among these protocols: Irrigation with needles, Manual dynamic agitation, Endoactivator, passive ultrasonic irrigation, all shown promising results on debris and smear layer removal ${ }^{(23)}$. There is a debate in literature about the action of these systems in eradication of microorganism ${ }^{(9,24,25)}$.

The results of our study regarding the antibacterial effect of both of the testing solutions with different agitation protocols came with increase in the bacterial count reduction with no statistical difference between $\mathrm{QMix}^{\mathrm{TM}} 2 \mathrm{in} 1$ and $2.5 \% \mathrm{NaOCl}$ after 3 days period from the irrigation procedures. This finding is in full agreement with the study conducted by $\mathbf{M a}$ et $\boldsymbol{a l}^{(19)}$. The current study used a methodology that mimics more the clinical environment.

Furthermore, our results came in agreement with the work of Stojicic $\boldsymbol{S}$ et al ${ }^{(20)}$ who used lower concentration of NaOCL (1\%) and tested different time intervals of application 5 seconds, 30 seconds and 3 minutes. Wang et al ${ }^{(14)}$ compared the antibacterial effect of $\mathrm{QMix}^{\mathrm{TM}} 2 \mathrm{in} 1$ to $6 \% \mathrm{NaOCl}$ on young and old Enterococcus faecalis biofilms. They found that both irrigants were as effective in killing young Enterococcus faecalis biofilms. The results of their studies also agree with the present study.

These findings disagree with the results reached by Morgental et al ${ }^{(26)}$ who compared the antimicrobial effect of $6 \% \mathrm{NaOCl}$ and $\mathrm{QMix}^{\mathrm{TM}} 2 \mathrm{in} 1$ in the presence of dentine powder, results proved that $6 \% \mathrm{NaOCl}$ was more effective than $\mathrm{QMix}^{\mathrm{TM}} 2 \mathrm{in} 1$ against Entercoccus facealis.

The difference in results might be attributed to the techniques used in infection or different strains of Enterococcus faecalis used as well as the concentration of initial bacterial inoculum. The latter study used bovine dentin that may have caused difference due to its buffering effect.

The results of the present study also showed increasing the effect of $\mathrm{QMix}^{\mathrm{TM}} 2 \mathrm{in} 1$ over $2.5 \% \mathrm{Na}$ $\mathrm{OCl}$ after 10 days of incubation period of microorganisms from the irrigation procedures. This finding is in agreement with Wang et al ${ }^{(27)}$ who examined the effect of smear layer of infected dentin blocks with Enterococcus faecalis on the antibacterial effect of 2\%, 6\% NaOCl, 2\% CHX and QMix ${ }^{\mathrm{TM}} 2 \mathrm{in} 1$. Results showed the superiority of QMix ${ }^{\mathrm{TM}} 2 \mathrm{in} 1$ in its antibacterial action against $2 \% \mathrm{NaOCl}$. Moreover Neglia et al ${ }^{(28)}$ and Tirali et al ${ }^{(29)}$ recorded that sodium hypochorite has a low antimicrobial efficiency against Enterococcus Faecalis, they also added that increasing sodium hypochorite concentration increases the antimicrobial properties.

Results may be attributed to ability of $\mathrm{QMix}^{\mathrm{TM}} 2 \mathrm{in} 1$ at 10 minutes to remove much of the smear layer and this produces a gradually increasing effect on the dentine bacteria by a synergistic effect of its antibacterial components. The killing by QMix $^{\mathrm{TM}} 2 \mathrm{in} 1$ increased more than $100 \%$ whereas the killing by $2 \%$ and $6 \% \mathrm{NaOCl}$ increased only by $10 \%$. These findings disagree with results reached by Ma et al ${ }^{(19)}$, Stojicic S et al ${ }^{(20)}$, Wang et al ${ }^{(14)}$ who stated that $\mathrm{QMix}^{\mathrm{TM}} 2 \mathrm{in} 1$ is as effective as $\mathrm{NaOCl}$ in bacterial eradication. Difference in results may be attributed to difference in methodology between the previous studies that subjected the samples to 5 seconds, 30 seconds, 3 minutes and 5 minutes exposure to different irrigating solutions and the current study in which the exposure was only for 1 minute with replenishment every 20 seconds. Furthermore, samples of this study were taken at different time intervals to determine its prolonged efficacy of the tested irrigants.

Results of this study showed that as regarding total mean values of all final rinse techniques, no significant difference was found between the three 
techniques i.e. there wasn't any difference between different agitation techniques on the antibacterial activity of both irrigants used. These results agree with the results of several studies, Brito et al $^{(9)}$ who found that there was no statistically significant difference between conventional irrigation with Max-I-probe needles and activation of the irrigant by the Endoactivator system in intracanal bacterial reduction. Townsend and Maki ${ }^{(25)}$, recorded no statistical difference between conventional irrigation and EndoVac in bacterial eradication but there was statistical significant difference for the Ultrasonic, Endoactivator, F-File, and sonic agitation groups.

Furthermore, our results coincided with the work of Bhuva et al ${ }^{(30)}$ who showed no statistically significant difference when comparing the efficacy of passive ultrasonic irrigation with that of conventional syringe irrigation with $1 \%$ sodium hypochorite on intra-radicular Enterococcus faecalis biofilms.

These result disagree with De Gregorio et $\boldsymbol{a l}^{(31)}$ who demonstrated that needle irrigation alone showed significantly less penetration of irrigant that was limited to the level of penetration of the needle in comparison with sonic and ultrasonic. Furthermore, our results contradicted with the work of Cachovan et al ${ }^{(32)}$ who revealed that ultrasonic activated irrigation reduced bacterial counts significantly better than hydrodynamic irrigation and manual rinsing with $\mathrm{NaOCl}$. These differences between our studies and other studies may be attributed to the limitation of irrigation with the needle 2 to 3 $\mathrm{mm}$ beyond the needle tip which may minimize the cleaning efficacy of the manual irrigation making it insufficient to remove the intracanal bacteria compared to sonic and ultrasonic.Futhermore the acoustic streaming velocity and cavitation, which positively infuence debris removal and ensures better penetration of different irrigants in to dentinal tubules.

The present obeservation in our study suggest that irrigation with $\mathrm{QMix}^{\mathrm{TM}} 2 \mathrm{in} 1$ is as efficient as $2.5 \%$
$\mathrm{NaOCl}$ in short duration as well as the prolonged superiorty of $\mathrm{QMix}^{\mathrm{TM}} 2 \mathrm{in} 1$ over $2.5 \% \mathrm{NaOCl}$. Moreover Agitation using different techniques did not significantly improve the antimicrobial efficiency of the irrigants use.

\section{CONCLUSIONS}

QMixTM2in1 irrigating solution proved antimicrobial efficacy in short and prolonged duration against Enterococcus faecalis. The antimicrobial efficiency of sodium hypochlorite can be improved using full concentration. It was also concluded that different agitation techniques have no effect on the antimicrobial efficacy.

\section{REFRENCES}

1. Angles ML., Marshall KC. and Goodman AE.: Plasmid transfer between marine-bacteria in the aqueous phase and biofilms in reactor microcosms. Appl Environ Microbial., 59:843-50, 1993.

2. Hausner M. and Wuertz S.: High rates in conjugation in bacterial biofilms as determined by quantitative in situ analysis. Appl Environ Microbial., 65:3710-13, 1999.

3. Charles H. Stuart., Scott A., Schwartz., Thomas J. and Christopher B.: Enterococcus faecalis: It's role in root canal treatment failure and current concepts in retreatment. J Endod., 32:93-98, 2006.

4. Zehnder M. and Dent DM.: Root canal irrigants. J Endod., 32:389-98, 2006.

5. Spencer HR. and Brennan PA.: The use of sodium hypochlorite in endodontics- potential complications and their management. Brit. Dent. J., 9:555-59, 2007.

6. Leclerc R.: Sodium hypochlorite in endodontics. J Dent Que., 27:13-6, 1990.

7. Siquera JF., Rocas IN., Favieri A. and Lima KC.: Chemomechanical reduction of the bacterial population in the root canal after instrumentation and irrigation with $1 \%, 2.5 \%$, and $5.25 \%$ sodium Hypochlorite. J Endod., 26:331-4,2000.

8. Dai L., Khechen K., Khan S., Gillen B., Loushine BA., Wimmer CE., Gutmann JL., Pashley D. and Tay FR.: The effect of QMixTM2in1, an experimental antibacterial root canal irrigant, on removal of canal wall smears layer and debris. J Endod., 37:80-4, 2011. 
9. Brito PRR., Souza LC., Machado de Oliveira JC., Alves FR., De-Deus G., Lopes HP. and Siqueira JF Jr.: Comparison of the effectiveness of three irrigation techniques in reducing intracanal Enterococcus faecalis populations: An In Vitro Study. J Endod., 35:1422-7, 2009

10. Tronstad L., Barnett F., Schwartzben L. and FrascaP.: Effective and safety of a sonic vibratory endodontic instrument. Endod Dent Traumatol., 1:69-76, 1985.

11. Ruddle C.: Hydrodynamic disinfection: Tsunami endodontics. Dent Today., 26:110-7, 2007.

12. Richman M.: Use of ultrasonics in root canal therapy and root resections. J Dent Med., 12:12-8, 1957.

13. Weller RN, Brady JM. and Bernier WE.: Efficacy of ultrasonic cleaning. J Endod., 6:740-3, 1980.

14. Wang Z., Shen Y. and Haapasalo M.: Effectiveness of endodontic disinfecting solutions against young and old Enterococcus faecalis biofilms in dentin canals. J Endod., 38:1376-79, 2012.

15. Kishen A., Chen N., Tan L. and Asundi, A.: Chairside Sensor for Rapid Monitoring of Enterococcus faecalis Activity. J Endod., 30: 872-5,2004.

16. Sundqvist G., Figdor D., Persson S. and Sjo“ gren U.: Microbiologic analysis of teeth with failed endodontic treatment and the outcome of conservative retreatment. Oral Surg. Oral Med. Oral Pathol. Oral Radiol. Endod., 85: 86-93,1998.

17. Haffajee AD., Cugini MA., Dibart S., Smith C., Kent RL Jr. and Socransky SS.: Clinical and microbiological features of subjects with adult periodontitis who responded poorly to scaling and root planing. J Clin. Periodontol., 24: 76776, 1997.

18. Spencer HR. and Brennan PA.: The use of sodium hypochlorite in endodontics- potential complications and their management. Brit. Dent. J., 9:555-59, 2007.

19. Ma J., Wang Z., Shen Y. and Haapasalo M.: New noninvasive model to study the effectiveness of dentin disinfection by using confocal laser scanning microscopy. J Endod., 10:1380-5, 2011.

20. Stojicic S., Shen Y., Qian W., Johnson B. and Haapasalo M.: Antibacterial and smear layer removal ability of a novel irrigant, QMix. Int Endod J., 45:363-71, 2011.

21. Abidal AA., Abdul-Rahman GY. and Tawfeeq AW.: The antibacterial effect of QMix, a novel root canal irrigant. AL-Rafidain Dent J., 13:537-46, 2012.
22. ChandrasekharV.,AmulyaV.,RaniVS.,PrakashTJ.,Ranjani AS. and Gayathri CH.: Evaluation of biocompatibility of a new root canal irrigant QMixTM2in1. J Endod., 16:3640, 2013.

23. Paragliola R., Franco V., Fabiani C., Mazzoni A., Nato F., Tay FR., Breschi L. and Grandini S.: Final rinse optimization: influence of different agitation protocols. $\mathrm{J}$ Endod., 36:282-5, 2010.

24. Howard RK., Kirkpatrick TC., Rutledge RE. and Yaccino JM.: Comparison of debris removal with three different irrigation techniques. J Endod., 37:1301-05, 2011.

25. Townsend C. and Maki J.: An in vitro comparison of new irrigation and agitation techniques to ultrasonic agitation in removing bacteria from a simulated root canal. J Endod., 35:1040-3, 2009.

26. Morgental RD., Singh A., Sappal H., Kopper PM.,VierPelisser FV. and Peters OA.: Dentin inhibits the antibacterial effect of new and conventional endodontic irrigants. J Endod., 39: 406-5, 2013.

27. Wang Z., Ya Shen. and Haapasalo M.: Effect of smear layer against disinfection protocols on Enterococcus faecalis infected dentin. J Endod., 39:1395-1400, 2013.

28. Neglia R., Ardizzoni A., Giardino L., Ambu E., Grazi S., Calignano S., Rimoldi C., Righi E. and Blasi E.: Comparative in vitro and ex vivo studies on the bactericidal activity of Tetraclean, a new generation endodontic irrigant, and sodium hypochlorite. New Microbiol, 31:57-65, 2008.

29. Tirali RE., Turan Y., Akal N. and Karahan ZC.: In vitro antimicrobial activity of several concentrations of $\mathrm{NaOCl}$ and Octenisept in elimination of endodontic pathogens. Oral Surg. Oral Med. Oral Pathol. Oral Radiol. Endod., 108:117-20, 2009.

30. Bhuva B., Patel S., Wilson R., Niazi S., Beighton D. and Monnocci F.: The effectivness of passive ultrasonic irrigation on intra-radicular Enterococcus Faecalis biofilms in extracted single-rooted human teeth. Int Endod J., 43:241-50, 2010.

31. De Gregorio C., Estovez R. and Cismeros R.: Effect of EDTA, sonic and ultrasonic activation on the penetration of sodium hypochorite into simulated lateral canal, an in vitro study. J Endod., 35:891-95, 2009.

32. Cachovan G., Schiffner U., Altenhof S., Guentsch A., Pfister W. and Eick S.: Comparative antibacterial efficacies of hydrodynamic and ultrasonic irrigation systems in vitro. J Endod., 39: 1171-5,2013. 